\title{
Caroline Surmann, Cinéma et théâtre chez Jean Cocteau. Intermédialité et esthétique
}

\section{Mireille Brangé}

\section{(2) OpenEdition}

1 Journals

\section{Édition électronique}

URL : http://journals.openedition.org/studifrancesi/1620

DOI : 10.4000/studifrancesi. 1620

ISSN : 2421-5856

Éditeur

Rosenberg \& Sellier

\section{Édition imprimée}

Date de publication : 1 novembre 2014

Pagination : 635-636

ISSN : 0039-2944

\section{Référence électronique}

Mireille Brangé, "Caroline Surmann, Cinéma et théâtre chez Jean Cocteau. Intermédialité et esthétique », Studi Francesi [En ligne], 174 (LVIII | III) | 2014, mis en ligne le 01 novembre 2014, consulté le 18 septembre 2020. URL : http://journals.openedition.org/studifrancesi/1620 ; DOI : https://doi.org/ 10.4000/studifrancesi. 1620

Ce document a été généré automatiquement le 18 septembre 2020.

\section{(c)}

Studi Francesi è distribuita con Licenza Creative Commons Attribuzione - Non commerciale - Non opere derivate 4.0 Internazionale. 


\title{
Caroline Surmann, Cinéma et théâtre chez Jean Cocteau. Intermédialité et esthétique
}

\author{
Mireille Brangé
}

\section{RÉFÉRENCE}

CAROLINE SURMANN, Cinéma et théâtre chez Jean Cocteau. Intermédialité et esthétique, Paris, Classiques Garnier, 2012 («Etudes de littérature des $\mathrm{Xx}^{\mathrm{e}}$ et $\mathrm{XxI} \mathrm{I}^{\mathrm{e}}$ siècles»), pp. 332.

1 Dans une démarche artistique considérée comme essentiellement multimédiale et «déambulant entre les arts» (p. 12), la relation établie entre cinéma et théâtre par Cocteau est un terrain de choix pour envisager sa pratique intermédiale. L'A. précise ce concept travaillé d'abord en Allemagne et au Canada et le plus souvent seulement approché en France, et offre une introduction théorique appréciable (pp. 13-15; 47-67) en l'absence, à notre connaissance, de toute traduction française des textes de référence en la matière.

2 L'enjeu de la réflexion esthétique et non herméneutique (p. 17) est de montrer comment Cocteau «entrecroise et investit les passages et les intersections entre les médias faisant apparaître de nouvelles qualités esthétiques au-delà des divers genres et formes médiales établis» (p. 13) et comment il cherche très vite à transformer mutuellement les media pour affirmer leur singularité et leur caractère irremplaçable. L'A. ancre l'esthétique de Cocteau dans la modernité, définie essentiellement comme lieu de la "problématisation du sujet et de son rapport au réel» (p. 81) et du questionnement des processus de perception (p. 84). La poésie apparaissant comme stimulation des sens et expérience déstabilisante, le cinéma se révèle un des media et médiateurs idéaux d'exploration.

3 L'autre axe de la démonstration repose essentiellement sur l'exploration de la pensée et de l'esthétique de Cocteau, qui s'exprime dans son travail sur théâtre, théâtral et 
théâtralité, définie comme un mode de perception indépendant de la scène véritable. Cocteau a ainsi d'abord recherché un spectacle total libérant la poésie du théâtre de toute part littéraire et renouvelant les processus de perception (pp. 117-119). Dans Parade, Le Boeuf sur le toit, les allusions aux westerns, comédies et burlesques américains abondent. La rencontre avec Radiguet l'amène à voir dans le cinéma un moyen plus adéquat à cette recherche. Le Sang d'un poète, «film des arts», sera leur pendant cinématographique (p. 134). Tout en désirant une "délittérarisation" du cinéma, il explore alors un «théâtre d'actes» s'opposant à la fois au théâtre littéraire et symboliste, et au théâtre de mise en scène.

4 Après 1945 , ses films de théâtre explorent une nouvelle «théâtralité» apparemment à contre-courant d'une époque où le cinéma explore sa "cinématographicité» propre (p. 145). C'est un moyen de fixer (et non de reproduire) ses mises en scène et le modèle antinaturaliste et déclamatoire qu'il a toujours apprécié au théâtre mais aussi de révéler le caractère de simulacre du cinéma. L'A. compare les adaptations de L'Aigle à deux têtes et des Parents terribles pour saisir cette dialectique intermédiale. Cependant, le travail de Cocteau sur la vision est aussi remarquable dans les "films oniriques», «automythologiques» sinon autobiographiques (p. 191), où il met «en relief la médialité» du cinéma (théâtre, peinture, dessin) et «ses potentialités de simulacre» (p. 233). L'étude de La Belle et La Bête et d'Orphée montre que le cinéma pour Cocteau permet une synthèse, dépassant les pôles Bazin/Méliès, entre le réel et l'imaginaire en les apparentant mutuellement (p. 238). Le cinéma visualise l'invisible, dérègle les catégories de l'espace et du temps. Loin du touche-à-tout, Cocteau apparaît un expérimentateur soucieux du travail sur les formes esthétiques et modales et de la constante visibilité de ce travail d'une forme par une autre. 